\title{
Environmental analysis of building shallow foundations: the influence of prefabrication, typology, and structural design codes
}

Citation for published version (APA):

Pujadas-Gispert, E., Sanjuan-Delmás, D., \& Josa, A. (2018). Environmental analysis of building shallow foundations: the influence of prefabrication, typology, and structural design codes. Journal of Cleaner Production, 186, 407-417. https://doi.org/10.1016/j.jclepro.2018.03.105

DOI:

10.1016/j.jclepro.2018.03.105

Document status and date:

Published: 10/06/2018

Document Version:

Typeset version in publisher's lay-out, without final page, issue and volume numbers

Please check the document version of this publication:

- A submitted manuscript is the version of the article upon submission and before peer-review. There can be important differences between the submitted version and the official published version of record. People interested in the research are advised to contact the author for the final version of the publication, or visit the $\mathrm{DOI}$ to the publisher's website.

- The final author version and the galley proof are versions of the publication after peer review.

- The final published version features the final layout of the paper including the volume, issue and page numbers.

Link to publication

\footnotetext{
General rights

- You may freely distribute the URL identifying the publication in the public portal. follow below link for the End User Agreement:

www.tue.nl/taverne

\section{Take down policy}

If you believe that this document breaches copyright please contact us at:

openaccess@tue.nl

providing details and we will investigate your claim.
}

Copyright and moral rights for the publications made accessible in the public portal are retained by the authors and/or other copyright owners and it is a condition of accessing publications that users recognise and abide by the legal requirements associated with these rights.

- Users may download and print one copy of any publication from the public portal for the purpose of private study or research.

- You may not further distribute the material or use it for any profit-making activity or commercial gain

If the publication is distributed under the terms of Article 25fa of the Dutch Copyright Act, indicated by the "Taverne" license above, please 


\title{
Environmental analysis of building shallow foundations: The influence of prefabrication, typology, and structural design codes
}

\author{
Ester Pujadas-Gispert ${ }^{\mathrm{a}, *}$, David Sanjuan-Delmás ${ }^{\mathrm{b}}$, Alejandro Josa ${ }^{\mathrm{c}}$ \\ a School of Architecture, Universitat Politècnica de Catalunya (UPC), Barcelona, Spain \\ b Sostenipra Research Group (SGR 01412), Institute of Environmental Sciences and Technology (MDM-2015-0552), Z Building, Autonomous University of Barcelona (UAB), \\ Bellaterra, Barcelona, Spain \\ ${ }^{\mathrm{c}}$ Department of Civil and Environmental Engineering (DECA), School of Civil Engineering (Escola de Camins), Sustainability Institute (IS.UPC), Universitat Politècnica de \\ Catalunya (UPC), Barcelona, Spain
}

\section{A R T I C L E I N F O}

\section{Article history:}

Received 30 September 2017

Received in revised form 17 January 2018

Accepted 9 March 2018

Available online xxx

Keywords:

Shallow foundation

Life cycle assessment

Building

Concrete

EC-2

EHE-08

\begin{abstract}
A B S T R A C T
The design of building foundations has usually been based on tradition, local practice, experience, and structural design codes. Safety is invariably considered the main factor and environmental criteria (or, in general, sustainability) is seldom given due consideration. However, similar safety indicators can be achieved with different variables and a minimum safety factor must always be ensured. The main objective of this study is, from an environmental perspective, to assess the influence of the construction system (cast-in-situ or precast), foundation type (rigid or flexible), and structural code (EC-2 or EHE-08) in the case of a concrete shallow foundation (CSF), using Life Cycle Assessment (LCA). Applying this methodology, the materials (concrete and steel) yielded the highest impacts in all categories, at around $95 \%$ for cast-in-situ CSFs and at around $85 \%$ for precast CSFs, both in relation to global warming. Consequently, optimization of the amount of these materials is crucial when considering the particular variables selected in this study. The results showed that cast-in-situ and flexible CSFs at moderately shallow depths (and therefore with less steel reinforcement) and precast CSFs with considerable reductions in concrete volumes (due to sloped shapes) had lower environmental impacts. In addition, cast-in-situ CSFs constructed in accordance with the EHE-08 structural code showed lower impacts, while precast CSFs complying with the EC-2 code were environmentally preferable. However, a specific study might be required for specific factors in each case (loads, soil type, structural settlement, among others). Relevant environmental effects associated with the three variables should therefore be given specific consideration in the development of structural design codes and future constructions.
\end{abstract}

(C) 2018 .

\section{Introduction}

\subsection{Background}

It has been widely reported that buildings generate one third of Global Greenhouse Gas (GHG) emissions (UNEP, 2009a) and over $40 \%$ of global energy demand (UNEP, 2009b). The global population is projected to increase by $30 \%$ in 2050 (United Nations, 2017) and, as ever, new buildings will be necessary. According to quantitative data, the operational phase of the building is widely expected to dominate the life-cycle impact, mainly due to heating and cooling requirements (Ghattas et al., 2013). The embodied phase, which includes materials manufacturing and transportation, construction, maintenance, renovation, and demolition is expected to contribute $10-20 \%$ of the life-cycle impact of a building (UNEP, 2009b). Nevertheless,

\footnotetext{
* Corresponding author.

Email address: ester.pujadas@upc.edu (E. Pujadas-Gispert)
}

the embodied phase in low-energy buildings can represent as much as $50 \%$ of total life cycle impact (Ghattas et al., 2013). A high impact that is due to the lower impacts of the operational phase and the greater use of materials, especially energy intensive materials (Sartori and Hestnes, 2007). This study is focused on the foundation of the building, which is the part that transfers loads from the building or the structure to a suitable soil stratum. Ground movements, foundation, and plumbing can account for more than $60 \%$ of $\mathrm{CO}_{2}$ emissions in the construction of low-energy terraced houses (González and García Navarro, 2006). Moreover, foundation emissions are released over much shorter time spans when compared with the construction of the whole structure (Sandanayake et al., 2016). Unfortunately, environmental purposes are rarely taken into account in designing foundations (Ondova and Estokova, 2016), leaving much scope for improvement (Rose Inman and Houlihan Wiberg, 2015). Consequently, there is a need for approaches that will optimize resource consumption and reduce the environmental impacts of foundations to minimize the impact of the building stock. 


\subsection{Building shallow foundations}

Common building foundation types can briefly be classified into isolated concrete shallow foundations (CSFs) for individual columns, combined CSFs for several columns, and raft foundations for a whole building basement. From a structural point of view (EHE-08, 2008), CSFs can be considered rigid when the column-to-edge length of the footing, $v$, is less than or equal to twice the depth $h(v \leq 2 h)$; and CSFs are flexible when $v>2 h$ (Fig. 1). Obviously, rigid CSFs require less steel reinforcement than flexible CSFs. In addition, foundations can bear directly on the ground (shallow foundations) or they can incorporate piles that transfer the load to a deeper load-bearing stratum (deep foundations).

In addition, CSFs tend to present prismatic shapes. Two common types of CSF according to their shapes (Fig. 1) are studied here: the sloped CSF (a) and the single CSF (b). The former can provide substantial savings on concrete and reinforcement steel. However, sloped shapes are rarely built on site, as the reduction in the overall cost of the concrete is not compensated by the increased labour costs. Therefore, sloped shapes are normally precast, in a concrete casting process using reusable moulds or forms. The product is then cured in a controlled environment (normally a factory), transported to the construction site, hoisted and manoeuvred into position.

The above manufacturing process, known as prefabrication, generally occurs at a specialized facility where one or more components of a final installation are formed from various materials (Chiang et al., 2006). Widely adopted in building projects (Wong et al., 2003), prefabrication can be categorized into three types: semi-prefabricated (some cast-in-situ and other precast components); fully prefabricated (all building components independently prefabricated and mounted in situ); and volumetric modular building, which is fully built in the factory (Mao et al., 2013). Prefabrication has many benefits, including better supervision that improves the quality of the product, a design that is fixed in the early stage of construction, costs that tend to be lower, and a shorter construction time (Tam et al., 2007a). Prefabrication reduces the use of materials and solves most difficult geometric configurations that require complex forming procedures (Wong et al., 2003). The construction process is independent of weather conditions and on-site accidents are reduced (Kamali and Hewage, 2017); the site is cleaner and tidier; site malpractices, waste (Tam et al., 2007b), and GHG emissions are reduced (Mao et al., 2013); and subsequent waste handling activities are facilitated, which include waste sorting, reuse, recycling and disposal (Li et al., 2014). Nevertheless, some of the main drawbacks of prefabrication are inflexibility towards changes in the design (no adaptation to site characteristics); higher initial construction costs (industrial installation and design); the need for an initial investment in design development; limited space for placing prefabricated building components; and the limited experience of some contractors (Tam et al., 2007a). Moreover, problems joining prefabricated units can require skilled workers and specialized transportation (Chiang et al., 2006). Prefabrication is highly suit-

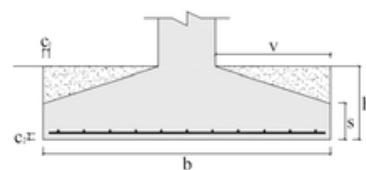

(a)

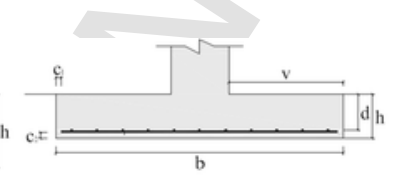

(b)
Fig. 1. Geometry and parameter definitions for (a) rigid sloped CSFs and (b) flexible single CSFs. Base $(b)$, depth $(h)$, footing column-to-edge length $(v)$, side depth $(s)$, lateral $\left(c_{1}\right)$ and bottom $\left(c_{2}\right)$ concrete covers and effective depth $(d)$. able for very repetitive construction processes, for mass production (Wong et al., 2003) and when speed and quality assurance are of importance in the construction process. Nevertheless, although prefabrication is common in building structures, it is unusual in building foundations, that depend on natural (soil) conditions, although it might be of interest to take advantage of the aforementioned benefits. It has recently been stated that prefabricated foundations can help to fulfil environmental regulations and to obtain a better energy code for buildings. These foundations are not only quicker to build, but they also reduce natural resources and waste and emit less $\mathrm{CO}_{2}$, compared to traditional cast-in-situ foundations (Wren, 2012).

The construction of a conventional foundation consists of four main steps: building a framework or digging the ground; levelling by pouring a base course of lean concrete; placing the steel reinforcement; and concreting the foundation. The foundation usually achieves the required strength after 28 days. Building a precast foundation on site is much faster, because works on site mainly consist of preparing the ground and installing the foundation. At times, digging and backfilling of trenches and soil compaction are also required; but once the foundation is mounted, it is ready to hold the load. In both cases the manufacturing and the transport of materials (concrete, precast units, ...) and finishing operations must be added.

One of the key points in foundation design is appropriate soil settlement to prevent subsidence of the building and to support its structural load, because the ground is heterogeneous and (different soil layers and water content) will vary over time. Thus, the properties and the conditions of the soil, structural loading, the type of building structure, and the permissible amount of differential settlement have to be carefully considered when selecting a suitable foundation. The design of a foundation consists of two main parts: the geotechnical one that determines the soil properties; and, the structural one that determines the reinforced concrete design. There are design codes for structures and foundations all around the world. The Eurocode that regulates geotechnical aspects is Eurocode 7: Geotechnical Design - Part 1: General Rules (EN, 1997-1, 2004). The Eurocode that governs the structural components is Eurocode 2: Design of concrete structures - Part 1-1: General rules and rules for buildings (EN, 1992-1-1, 2004). Spanish codes that regulate the design of a foundation are the Technical Building Code - Structural safety - Foundations (CTE-SE-C, 2008) in which shallow foundations appear in Section 4 and deep foundations in Section 5; and the EHE-08 Structural Concrete Code (EHE-08, 2008), in which foundations are addressed in article 58. Additionally, foundations may be designed either in flexure as a (deep) beam (Calavera Ruiz, 2008), or by applying a truss analogy (Ritter, 1899) where the concrete acts as the struts and tensile strength is added by reinforcement elements. According to (EHE-08, 2008), in rigid foundations, the most appropriate method of analysis is strut-and-tie modelling, while in flexible foundations, flexural methods are applied.

\subsection{Summary of the state of the art}

As stated above, although the environmental impacts of foundation construction are significant, the general tendency is not to consider them, prioritizing the initial cost (Pujadas et al., 2013) together with safety assurance (Tam et al., 2007a). The utility of the life-cycle assessment (LCA) method has been demonstrated as a tool to quantify the environmental impacts of buildings. LCA is used for environmental measurement of industrial processes and products, by examining the flow of energy, materials and their consumption, and waste released into the environment. It provides useful information to deci- 
sion-makers for environmental improvement (Abd Rashid and Yusoff, 2015).

The building materials used in shallow foundations cause a major part of their environmental impact, followed by equipment usage, and transportation. GHG emissions due to materials, equipment usage, and transportation, according to (Sandanayake et al., 2016), for the construction of a raft-type foundation of a high-rise residential building, were $67 \%, 19 \%$, and $14 \%$, respectively. There are several factors that might influence the environmental impact of a foundation. For instance, the building load will condition the type and dimensions of the foundation. Thus, a timber frame building will require a lower impact foundation compared to a brick or a masonry building (Monahan and Powell, 2011). Moreover, the selection of materials to build a foundation might also be relevant. (Ondova and Estokova, 2016) stated that a concrete raft (shallow) foundation, a common solution in Slovakia, is less sustainable than earthbag foundations, dry stone and mortared stone foundations, and rammed earth tire foundations. Even the replacement of only one part of the foundation with a lower energy material can be environmentally beneficial. For instance, the substitution of burnt clay brick for rubble (broken stone) in part of a shallow foundation resulted in substantially less embodied energy (from $6727 \mathrm{MJ}$ to $445 \mathrm{MJ}$ ) (Yasantha Abeysundara and Babel, 2010). The selection of the foundation material depends on various conditions (economical, tradition, climatic, etc.). Nevertheless, foundations are mainly built of concrete, which normally has the highest initial embodied energy, because of the large quantities that are used (Ondova and Estokova, 2016). The optimization of its consumption is therefore important. In this regard, the reduction of concrete in a shallow foundation by $40 \%$ can lead to a $20 \%$ reduction in the GWP emissions of the construction of a foundation. Furthermore, the selection of the shallow foundation type might reduce emissions by almost one third (Rose Inman and Houlihan Wiberg, 2015). The same study also suggested that the substitution of concrete for low-carbon concrete could also help to reduce emissions. Moreover, shallow foundations with good soil support are cheaper and easier to build for low loads than deep foundations, which are frequently selected because of geotechnical criteria. However, little literature has been found on the environmental assessment of isolated CSFs, a common foundation for buildings with frame structures. Hence, the intention behind this paper is to provide data on isolated CSFs and to address their environmental optimization through several significant variables.

\subsection{Objectives}

The goal of this study is to analyse isolated concrete shallow foundations (CSFs) from a structural and environmental perspective, considering the construction methods (cast in situ or precast), the foundation type (rigid or flexible), and the structural design codes (EC-2 or EHE-08). The specific objectives to achieve this goal are as follows: (1) to conduct a structural analysis with the variables under study, in order to determine the amounts of concrete and steel reinforcement for structurally equivalent alternatives; (2) to calculate, to evaluate, and to compare the environmental impacts of the equivalent alternatives using LCA; and, (3) to assess the influence of the three variables under study on the environmental burdens of CSFs, and by doing so to define specific design conclusions and recommendations.

\section{Materials and methods}

The integrated methodology applied for the determination of the structural and the environmental influence of the specific variables (construction system, foundation type and structural codes) included the selection of equivalent CSFs (Section 2.1), the definition of the functional unit (FU) (Section 2.2) and system boundaries (Section 2.3), the structural design (Section 2.4), and the LCA (Section 2.5), as well the corresponding data sources (Section 2.6).

\subsection{Alternative selection}

The following variables were considered for the definition of the alternatives:

- Construction system: cast in situ (I) (concrete is poured on site) or precast $(\mathrm{P})$ (concrete is poured in a specialized facility).

- Foundation type (according to EHE-08): rigid (R) $(v \leq 2 h)$ or flexible (F) $(v>2 h)$ (Fig. 1).

- Structural code: Eurocode 2 (EC2) (EN 1992-1-1, 2004) or Spanish EHE-08 (EHE) (EHE-08, 2008).

- Shape: sloped CSF, marked with an asterisk *, or single CSF (Fig. 1).

In addition, the following three scenarios were established, to assess the environmental performance of these alternatives:

- CSFs with the same amount of concrete (C) (only changing the amount of steel).

- CSFs with a reduced amount of concrete (D) (changing the amounts of concrete and steel)

- Taking into account the best flexible foundations resulting from the previous scenarios, a third one was considered with flexible CSFs, in order to analyse the variation in the amount of concrete, depending on the number of steel reinforcing bars (S) (same number of steel reinforcing bars, different amounts of concrete).

The selected alternatives alongside their respective abbreviations are shown in Table 1.

Foundations with a rigid behaviour were calculated with strut-and-tie models, while CSFs with a flexible behaviour were calculated with flexural methods, in line with structural design codes. The foundations also complied with the minimum amount of reinforcement established in each code. In addition, all CSFs were calculated as single CSFs, while precast CSFs were also calculated as sloped units (Fig. 1). In this regard, precast sloped shapes are economically viable and represent a great reduction in concrete and steel reinforcement. Moreover, the structural results were verified with CYPECAD structural software (CYPE Ingenieros, 2017). Nevertheless, certain limitations were considered: the precast sloped CSFs calculated with EC-2 had a minimum depth ( $h$ in Fig. 1$)$ of $30 \mathrm{~cm}$ and a minimum side depth ( $s$ in Fig. 1) of $15 \mathrm{~cm}$ (CYPE Ingenieros, 2017). All the CSFs (single and precast) calculated with EHE-08 had a minimum depth $(h)$ of $25 \mathrm{~cm}$ (EHE-08, 2008), and the precast sloped CSFs calculated with EHE-08 had a minimum side depth $(s)$ of $25 \mathrm{~cm}$ (EHE-08, 2008).

Furthermore, precast CSFs have thinner concrete covers $\left(c_{1}\right.$ and $c_{2}$ in Fig. 1) compared to cast-in-situ CSFs, because factory construction processes tend to be more controlled, increasing reliability and pro-

Table 1

Abbreviations used for concrete shallow foundations.

\begin{tabular}{lllll}
\hline $\begin{array}{l}\text { Construction } \\
\text { system }\end{array}$ & $\begin{array}{l}\text { Foundation } \\
\text { type }\end{array}$ & Scenarios & $\begin{array}{l}\text { Structural } \\
\text { code }\end{array}$ & Shape \\
\hline I (cast in situ) & R (rigid) & $\begin{array}{l}\text { C (same amount of } \\
\text { concrete) }\end{array}$ & EC2 & (single) \\
$\mathbf{P}$ (precast) & F (flexible) & $\begin{array}{l}\text { D (reduced amount of } \\
\text { concrete) } \\
\text { S (same number of } \\
\text { reinforcing bars) }\end{array}$ & $\mathbf{E H E}$ & $*$ \\
(sloped) \\
\hline
\end{tabular}


viding quality guarantees, and because precast concrete is of a lower porosity and has a higher strength. In addition, the cover dimensions also vary depending on the structural code and whether the CSF is poured over prepared ground (including binding layers) or directly onto the soil. The thinner the concrete covers, the longer the reinforcing bars, implying more kilogrammes of steel reinforcement. Additionally, cast-in-situ CSFs are built on a 0.1 m layer of lean concrete, while precast CSFs are positioned directly onto the ground, because the concrete is already hardened and can not be contaminated.

\subsection{Functional unit (FU)}

The FU considered in this analysis is an isolated shallow CSF that can withstand a $0.4 \times 0.4 \mathrm{~m}$ column with a dead load of $400 \mathrm{kN}$ and an imposed load of $150 \mathrm{kN}$, built on a silty soil with a bearing pressure of $150 \mathrm{kN} / \mathrm{m}^{2}$, without the presence of a water table, seismicity, or chemical action, and designed for a service life of 50 years. These values were selected as a reference for the FU, because they are common for pillar sections, ground characteristics and loads, though other options are also possible. If the soil conditions are worse and the loads are heavier, then the shallow foundations will be larger, requiring more materials, earthworks, and installation, thereby increasing the environmental impacts. Besides, other specific conditions may require different alternative solutions such as deep foundations.

\subsection{System boundaries}

As shown in Fig. 2, the life cycle of a CSF is conditioned by: (1) the extraction and processing of raw materials; (2) the product manufacture (cast-in-situ concrete is usually mixed in the truck mixer while transported to the site and precast concrete is manufactured in a factory and transported by lorry to the site as a finished unit); (3) earthworks (all CSFs require excavation, but sloped CSFs also especially require backfill and compaction); (4) CSF construction; (5) maintenance during the service life of the CSF, usually 50 years or more; and, (6) decommissioning, possible recycling, and end of life. The life-cycle phases in this case run from the extraction of materials and their processing up until completion of the on-site construction. Moreover, each phase includes the impact of transportation. The excavated soil is transported and reused in another work or dumped in landfill sites, although it is also partly reused as backfill to cover the precast sloped CSFs. The service and maintenance life-cycle phase was excluded, because a well-designed foundation will need no maintenance or repairs throughout its lifespan and will therefore have no significant environmental impacts. Similarly, the decommissioning, possible recycling, and the end-of-life phases were not considered, because the foundation is usually left buried with no further action. Besides, the difference in environmental impacts between the alternatives during the excluded phases can be considered very low.

\subsection{Structural design}

The aim of the structural design is to analyse the specific variables (construction system, foundation type and structural codes) selected for the study and their influence on the quantity of materials required for the construction of CSFs. The basis of structural design states that a structure shall be designed and executed in such a way that ensures safety, serviceability, and durability. The recommended method is limit state design in conjunction with the partial factor method (EN 1991-1-1, 2002). One criterion for a safe design is that the structure should not reach two important limit states during its design life: U1timate Limit State (ULS) and Serviceability Limit State (SLS). The normal practice is to design CSFs for the Ultimate Limit State, to check the Serviceability Limit State, and to take all necessary precautions to ensure the durability of the structure. The Ultimate Limit State (ULS) is therefore a guarantee of structural safety. Partial factors that increase constructive actions and decrease material strengths are applied, in order to simulate the worst situation that a structure could encounter. Both the EC- 2 and the EHE- 08 codes state that the ultimate design load is $1.35 \mathrm{G}_{\mathrm{k}}+1.50 \mathrm{Q}_{\mathrm{k}}$, where $\mathrm{G}_{\mathrm{k}}$ is the characteristic dead load (self-weight) and $\mathrm{Q}_{\mathrm{k}}$ is the imposed load (external). In contrast, the Serviceability Limit State (SLS) reflects the functionality of the structure or structural members under normal use, individual comfort, and the appearance of the construction works (vibrations, deflections, and cracking).

In accordance with common practice, concrete compression strengths of $25 \mathrm{MPa}$ for cast-in-situ CSFs and $45 \mathrm{MPa}$ for precast CSFs were selected. CSFs were built in a general exposure class for foundations (a type of surrounding environment): XC2 (wet, rarely dry; corrosion induced by carbonation) for EC-2, and IIa (high humidity; corrosion of different origin than chlorides) for EHE-08, both of which are equivalent. Accordingly, the cement content was considered of $280 \mathrm{~kg} / \mathrm{m}^{3}$ for cast-in-situ concrete, while $400 \mathrm{~kg} / \mathrm{m}^{3}$ for precast concrete. Moreover, partial factors for concrete will vary depending on whether they are calculated with EC-2 (1.5 for cast in situ, 1.4 for precast) or with EHE-08 (1.5 for cast in situ, 1.35 for precast). The same type of steel (B-500-S) and the same partial factor (1.15) were selected for reinforcement.

\subsection{Life-cycle assessment}

The methodology applied for the calculation of the environmental impacts is Life Cycle Assessment (LCA) in accordance with ISO 14040 (ISO 14040:2006) and ISO 14044 (ISO 14044:2006). SimaPro 8.2.3.0 (PRé Consultants, 2016) software was used, together with the ReCiPe midpoint Hierarchist calculation method (Goedkoop et al., 2013). All environmental information was taken from the Ecoinvent v3.3 database (Swiss Centre for Life Cycle Inventories, 2016).

System boundaries

\begin{tabular}{|c|c|c|c|c|c|}
\hline $\begin{array}{l}\text { RAW MATERIAL } \\
\text { EXTRACTION }\end{array}$ & PRODUCTION & EARTHWORKS & CONSTRUCTION & $\begin{array}{l}\text { USE } \\
\text { PHASE }\end{array}$ & $\begin{array}{l}\text { END OF } \\
\text { LIFE }\end{array}$ \\
\hline $\begin{array}{l}\text { - Raw materials } \\
\text { - Transportation }\end{array}$ & $\begin{array}{l}\text { Cast in situ } \\
\text { - Concrete } \\
\text { - Steel reinforcement } \\
\text { - Transportation } \\
\text { Precast } \\
\text { - Precast components } \\
\text { - Transportation }\end{array}$ & $\begin{array}{l}\text { Diesel for: } \\
\text { - Excavation } \\
\text { - Backfill and } \\
\text { compaction } \\
\text { (only sloped) } \\
\\
\text { Transport of excess } \\
\text { soil to landfill site }\end{array}$ & $\begin{array}{l}\text { Diesel for: } \\
\text { - Construction } \\
\text { (cast in situ) } \\
\\
\text { - Installation } \\
\text { (precast) }\end{array}$ & & \\
\hline
\end{tabular}

Fig. 2. Diagram of the system under analysis. 
The following 7 midpoint impact categories were considered for the assessment according to the environmental product declaration of construction products (EN 15804:2012+A1:2014, 2014): Global warming potential (GWP, $\mathrm{kg} \mathrm{CO}_{2}$ eq), Ozone depletion potential (ODP, kg CFC-11 $1_{\mathrm{eq}}$ ), Terrestrial acidification potential (TAP, kg $\mathrm{SO}_{2 \mathrm{eq}}$ ), Freshwater eutrophication potential (FEP, kg $\mathrm{P}_{\mathrm{eq}}$ ), Photochemical oxidant formation potential (POFP, $\mathrm{kg}$ NMVOC), Mineral depletion potential (MDP, $\mathrm{kg} \mathrm{Fe}$ eq), and Fossil depletion potential (FDP, $\mathrm{kg}$ oil $_{\mathrm{eq}}$ ). Additionally, a particularly interesting midpoint impact category has in this case been added: Cumulative Energy Demand (CED, $\mathrm{MJ})$.

\subsection{Data sources}

Data on the amount of energy and materials used in CSF construction processes (inventory) were extracted from the database of the Institute of Construction Technology of Catalonia (ITeC, 2017). Concrete pumping and vibration were not considered, because a preliminary analysis attached no significant environmental impacts in the FU. The decrease in concrete volume during curing was set at $5 \%$ according to (Hormiconsa, 2011). The following standard average distances shown in Table 2 and used in previous studies were considered for the transportation of materials (Sanjuan-Delmás et al., 2015).

With regard to the manufacture of the reinforced concrete, the distances from their respective places of production to the (precast) concrete plant were set at $75 \mathrm{~km}$ for cement, at $40 \mathrm{~km}$ for aggregates, and at $130 \mathrm{~km}$ for steel reinforcements. Likewise, the distance for concrete from the concrete plant to the construction site was set at $30 \mathrm{~km}$, while the distance for the excess soil from the construction site to the landfill site was $30 \mathrm{~km}$. The report from (The Concrete Centre, 2009), stated that precast products are normally transported $150 \mathrm{~km}$ from the precast concrete plant to the construction site.

\section{Results and discussion}

\subsection{Structural analysis of CSFS}

Three scenarios $(C, D, S)$ were considered when studying the variables selected in the study (I-P, R-F,EC2-EHE), as shown in Table 1. The results of the structural study are shown in Table 3. All the alternatives share the same loads, soil characteristics, external conditions and safety indicators, in accordance with the buildings codes that are applied. It should be kept in mind that the larger the concrete volume of the CSF, the greater the weight and the base, so that total downward load is transferred to the ground with the same pressure. As will be noted, the concrete volumes of the precast CSFs were frequently smaller than the cast-in-situ CSFs. This difference is explained by the use of sloped shapes and better compensation of the bending moment, because the effective depth of the precast CSFs ( $d$ in Fig. 1) is

Table 2

Transport distances of building materials.

\begin{tabular}{|c|c|c|c|}
\hline Building material & Transportation & & Distance $(\mathrm{km})$ \\
\hline & From & To & \\
\hline Cement & Place of production & $\begin{array}{l}\text { Concrete plant } \\
\text { Precast concrete plant }\end{array}$ & 75 \\
\hline Aggregates & Place of production & $\begin{array}{l}\text { Concrete plant } \\
\text { Precast concrete plant }\end{array}$ & 40 \\
\hline Steel reinforcement & Place of production & $\begin{array}{l}\text { Construction site } \\
\text { Precast concrete plant }\end{array}$ & 130 \\
\hline Concrete & Place of production & Construction site & 30 \\
\hline Precast units & Precast concrete plant & Construction site & 150 \\
\hline
\end{tabular}

greater, due to its thinner concrete cover at the bottom $\left(c_{2}\right.$ in Fig. 1). In addition, flexible CSFs usually present smaller concrete volumes compared to rigid CSFs. And with regard to building codes, EC-2 permits smaller concrete volumes, as there is no restriction on the depth $(h)$. Conversely, EHE-08 limits the minimum depth of a CSF to $25 \mathrm{~cm}$.

Analysing the amounts of reinforcement, it can be seen that rigid CSFs obviously require less reinforcement than flexible CSFs as they are deeper (less tensile stress and more compressive stress that the concrete withstands more easily). When the depth of a flexible CSF increases, it becomes more rigid, and therefore requires less reinforcement. Conversely, when the depth of a rigid CSF increases, it requires more steel reinforcement, because the formulas that define its minimum amount of reinforcement take the CSF depth into account for surface protection purposes (not for flexural reinforcement).

Furthermore, smaller diameter reinforcing bars imply less steel, because the amount can be adjusted better to the calculations and shorter anchoring lengths are required. Also, manoeuvrability during construction and cracking control are improved. In addition, EC-2 recommends that the minimum bar diameter should be larger than $8 \mathrm{~mm}$, while EHE-08 establishes a minimum diameter of $12 \mathrm{~mm}$. Accordingly, reinforcing bars of $12 \mathrm{~mm}$ for all alternatives were selected.

When the CSFs had the same amount of concrete (Fig. 3), the precast CSFs generally presented more steel reinforcement compared to the cast-in-situ CSFs. Precast CSFs generally have thinner concrete covers, so they contain more steel reinforcement for the same number of reinforcing bars. In addition, some minimum steel reinforcement formulas for CSFs are influenced by concrete strength. In that regard, precast products tend to have higher strength concretes, because of better quality control. Consequently, the precast rigid CSFs calculated with EC-2 (PR-C-EC2) presented 60\% more steel reinforcement compared to the version that was cast in situ (IR-C-EC2).

Moreover, the flexible CSFs had fewer reinforcing bars compared to the rigid CSFs calculated with EC-2, because of the minimum reinforcing formula (for both rigid and flexible CSFs) of EC-2 that takes into account the CSF section (base and depth) and concrete strength. Conversely, the flexible CSFs incorporated more reinforcement compared to the rigid CSFs calculated with EHE-08. Normally, the reinforcement of a rigid CSF is defined by the minimum reinforcement formula that takes into account the CSF section, while the reinforcement of a flexible CSF is normally defined by a bending formula.

With regard to codes, the rigid CSFs calculated with EHE-08 presented smaller amounts of reinforcement compared to those calculated with EC-2, because the minimum reinforcement formula (for rigid and flexible CSFs) of EC-2 takes concrete strength into account, unlike EHE-08. Consequently, PR-C-EHE presented up to 52\% less reinforcement compared to PR-C-EC2. Nevertheless, the precast flexible CSF calculated with the EHE-08 (PF-C-EHE) incorporated 8\% more reinforcement compared to EC-2 (PF-C-EC2), because the flexible CSFs calculated with EHE-08 need to meet the minimum mechanical amount (only for flexible CSFs), which significantly increases the amount of steel reinforcement at higher concrete strengths.

When the amount of concrete could be reduced (Fig. 4), the precast CSFs calculated with EC-2 presented the lowest volumes: $48 \%$ less concrete volume for rigid CSFs (PR-D-EC2*) and 21\% less for flexible CSFs (PF-D-EC2), compared to the cast-in-situ versions. This difference is due to the fact that EC-2 specifies no limitation on the depth of a CSF, unlike EHE-08 $(25 \mathrm{~cm})$. Therefore, the difference between codes can represent a decrease of up to $33 \%$ of the concrete volume (PR-D-EHE* compared to PR-D-EC2*). Note that the pre- 
Table 3

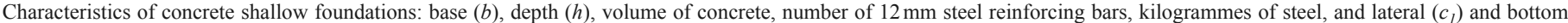
$\left(c_{2}\right)$ concrete covers.

\begin{tabular}{|c|c|c|c|c|c|c|c|c|c|c|}
\hline \multicolumn{3}{|l|}{ Scenarios and variables } & \multirow{2}{*}{$\begin{array}{l}\text { Concrete shallow foundations } \\
\text { IR-C-EC2 }\end{array}$} & \multirow{2}{*}{$\frac{b(\mathrm{~m})}{2.02}$} & \multirow{2}{*}{$\frac{h(\mathrm{~m})}{0.60}$} & \multirow{2}{*}{$\frac{\text { Concrete }\left(\mathrm{m}^{3}\right)}{2.45}$} & \multirow{2}{*}{$\frac{\varnothing(\mathrm{u})}{14}$} & \multirow{2}{*}{$\frac{\text { Steel }(\mathrm{kg})}{46.45}$} & \multirow{2}{*}{$\frac{c_{l}(\mathrm{~m})}{0.075}$} & \multirow{2}{*}{$\frac{c_{2}(\mathrm{~m})}{0.030}$} \\
\hline Same amount of concrete & $\mathrm{EC}-2$ & Rigid & & & & & & & & \\
\hline & & & PR-C-EC2 & 2.02 & 0.60 & 2.45 & 21 & 74.14 & 0.015 & 0.015 \\
\hline & & Flexible & IF-C-EC2 & 1.97 & 0.30 & 1.16 & 13 & 41.86 & 0.075 & 0.030 \\
\hline & & & PF-C-EC2 & 1.97 & 0.30 & 1.16 & 12 & 41.19 & 0.015 & 0.015 \\
\hline & EHE-08 & Rigid & IR-C-EHE & 2.02 & 0.60 & 2.45 & 10 & 33.00 & 0.080 & 0.030 \\
\hline & & & PR-C-EHE & 2.02 & 0.60 & 2.45 & 10 & 35.27 & 0.016 & 0.016 \\
\hline & & Flexible & IF-C-EHE & 1.97 & 0.30 & 1.16 & 13 & 41.63 & 0.080 & 0.030 \\
\hline & & & PF-C-EHE & 1.97 & 0.30 & 1.16 & 13 & 44.58 & 0.016 & 0.016 \\
\hline \multirow{9}{*}{ Reduced amount of concrete } & EC-2 & Rigid Flexible & IR-D-EC2 & 1.98 & 0.40 & 1.57 & 10 & 32.48 & 0.075 & 0.030 \\
\hline & & & PR-D-EC2* & 1.96 & 0.40 & 0.81 & 12 & 41.00 & 0.015 & 0.015 \\
\hline & & & IF-D-EC2 & 1.96 & 0.25 & 0.95 & 18 & 57.64 & 0.075 & 0.003 \\
\hline & & & PF-D-EC2 & 1.95 & 0.20 & 0.75 & 19 & 64.58 & 0.015 & 0.015 \\
\hline & & & PF-D-EC2* & 1.95 & 0.31 & 0.81 & 14 & 47.66 & 0.015 & 0.015 \\
\hline & EHE-08 & Rigid & IR-D-EHE & 1.98 & 0.40 & 1.57 & 10 & 32.31 & 0.080 & 0.030 \\
\hline & & & PR-D-EHE* & 1.97 & 0.40 & 1.21 & 12 & 41.17 & 0.016 & 0.016 \\
\hline & & Flexible & IF-D-EHE & 1.96 & 0.25 & 0.96 & 16 & 50.95 & 0.080 & 0.030 \\
\hline & & & PF-D-EHE & 1.96 & 0.25 & 0.96 & 15 & 51.17 & 0.016 & 0.016 \\
\hline \multirow[t]{34}{*}{ Same number of reinforcing bars } & $\mathrm{EC}-2$ & Cast in situ & IF-S10-EC2 & 1.98 & 0.38 & 1.48 & 10 & 32.47 & 0.075 & 0.030 \\
\hline & & & IF-S11-EC2 & 1.97 & 0.35 & 1.37 & 11 & 35.56 & 0.075 & 0.030 \\
\hline & & & IF-S12-EC2 & 1.97 & 0.33 & 1.27 & 12 & 38.70 & 0.075 & 0.030 \\
\hline & & & IF-S13-EC2 & 1.96 & 0.30 & 1.16 & 13 & 41.84 & 0.075 & 0.030 \\
\hline & & & IF-S14-EC2 & 1.96 & 0.28 & 1.09 & 14 & 44.98 & 0.075 & 0.030 \\
\hline & & & IF-S15-EC2 & 1.96 & 0.27 & 1.03 & 15 & 48.11 & 0.075 & 0.030 \\
\hline & & & IF-S16-EC2 & 1.96 & 0.26 & 1.00 & 16 & 51.29 & 0.075 & 0.030 \\
\hline & & & IF-S17-EC2 & 1.96 & 0.26 & 0.98 & 17 & 54.47 & 0.075 & 0.030 \\
\hline & & & IF-S18-EC2 & 1.96 & 0.25 & 0.95 & 18 & 57.64 & 0.075 & 0.030 \\
\hline & & & IF-S19-EC2 & 1.95 & 0.24 & 0.93 & 19 & 60.81 & 0.075 & 0.030 \\
\hline & & Precast & PF-S12-EC2 & 1.97 & 0.31 & 1.20 & 12 & 41.19 & 0.015 & 0.015 \\
\hline & & & PF-S12-EC2* & 1.95 & 0.37 & 0.91 & 12 & 40.94 & 0.015 & 0.015 \\
\hline & & & PF-S13-EC2 & 1.96 & 0.29 & 1.10 & 13 & 44.54 & 0.015 & 0.015 \\
\hline & & & PF-S13-EC2* & 1.95 & 0.34 & 0.87 & 13 & 44.30 & 0.015 & 0.015 \\
\hline & & & PF-S14-EC2 & 1.96 & 0.27 & 1.04 & 14 & 47.89 & 0.015 & 0.015 \\
\hline & & & PF-S14-EC2* & 1.95 & 0.31 & 0.81 & 14 & 47.66 & 0.015 & 0.015 \\
\hline & & & PF-S15-EC2 & 1.95 & 0.25 & 0.94 & 15 & 51.20 & 0.015 & 0.015 \\
\hline & & & PF-S16-EC2 & 1.95 & 0.24 & 0.90 & 16 & 54.59 & 0.015 & 0.015 \\
\hline & & & PF-S17-EC2 & 1.95 & 0.22 & 0.84 & 17 & 57.91 & 0.015 & 0.015 \\
\hline & & & PF-S18-EC2 & 1.95 & 0.21 & 0.81 & 18 & 61.28 & 0.015 & 0.015 \\
\hline & & & PF-S19-EC2 & 1.95 & 0.20 & 0.75 & 19 & 64.58 & 0.015 & 0.015 \\
\hline & EHE-08 & Cast in situ & IF-S10-EHE & 1.98 & 0.38 & 1.49 & 10 & 32.24 & 0.080 & 0.030 \\
\hline & & & IF-S11-EHE & 1.97 & 0.36 & 1.38 & 11 & 35.38 & 0.080 & 0.030 \\
\hline & & & IF-S12-EHE & 1.97 & 0.33 & 1.27 & 12 & 38.49 & 0.080 & 0.030 \\
\hline & & & IF-S13-EHE & 1.96 & 0.30 & 1.16 & 13 & 41.61 & 0.080 & 0.030 \\
\hline & & & IF-S14-EHE & 1.96 & 0.29 & 1.10 & 14 & 44.73 & 0.080 & 0.030 \\
\hline & & & IF-S15-EHE & 1.96 & 0.27 & 1.02 & 15 & 47.85 & 0.080 & 0.030 \\
\hline & & & IF-S16-EHE & 1.96 & 0.25 & 0.96 & 16 & 50.95 & 0.080 & 0.030 \\
\hline & & Precast & PF-S12-EHE & 1.98 & 0.38 & 1.48 & 12 & 41.41 & 0.016 & 0.016 \\
\hline & & & PF-S12-EHE* & 1.97 & 0.39 & 1.19 & 12 & 41.15 & 0.016 & 0.016 \\
\hline & & & PF-S13-EHE & 1.97 & 0.32 & 1.23 & 13 & 44.60 & 0.016 & 0.016 \\
\hline & & & PF-S13-EHE* & 1.96 & 0.34 & 1.10 & 13 & 44.49 & 0.016 & 0.016 \\
\hline & & & PF-S14-EHE & 1.96 & 0.29 & 1.12 & 14 & 47.94 & 0.016 & 0.016 \\
\hline & & & PF-S15-EHE & 1.96 & 0.25 & 0.96 & 15 & 51.17 & 0.016 & 0.016 \\
\hline
\end{tabular}

Terminology: cast in situ (I); precast (P); rigid (R); flexible (F); calculated with EC-2 (EC2); calculated with EHE-08 (EHE).

cast flexible CSF calculated with EHE-08 (PF-D-EHE) presented the same volume of concrete as the cast-in-situ version (IF-D-EHE), due to the aforementioned limitation. In addition, the sloped shapes of precast CSFs mean that the amount of concrete and the steel reinforcement may be reduced. One example is the flexible sloped CSF calculated with EC-2 (PF-D-EC2*) that, even though it presented 9\% more concrete compared to the single version (PF-D-EC2), because of its greater depth, it required $26 \%$ less reinforcement. In contrast, the flexible CSF calculated with the EHE-08 (IF-D-EHE) required 12\% less reinforcement steel compared to the EC-2 version (IF-D-EC2) for a similar concrete section, because the former has slightly thicker concrete covers and the shear stress obtained by applying the formulas in EHE-08 is somewhat lower compared to EC-2. Neverthe- less, the reduction of the depth of a CSF normally implies more steel reinforcement, which implies greater adaptability of the CSF to the ground and cracks in the lower part are prevented (IF-D-EC2 compared to PF-D-EC2).

Fig. 5 depicts the third scenario, where the flexible CSFs presented the same number of reinforcing bars and different amounts of concrete (S). The cast-in-situ CSFs calculated with EC-2 (IF-EC2) showed a similar use of concrete compared to EHE-08 (IF-EHE), as differences between bending formulas and concrete covers between codes are compensated. Nevertheless, the precast CSFs calculated with EC-2 (PF-EC2 and PF-EC2*) presented lower amounts of concrete (PF-EHE and PF-EHE*). These lower amounts are usually because the flexible CSFs (and only the flexible CSFs) calculated with 


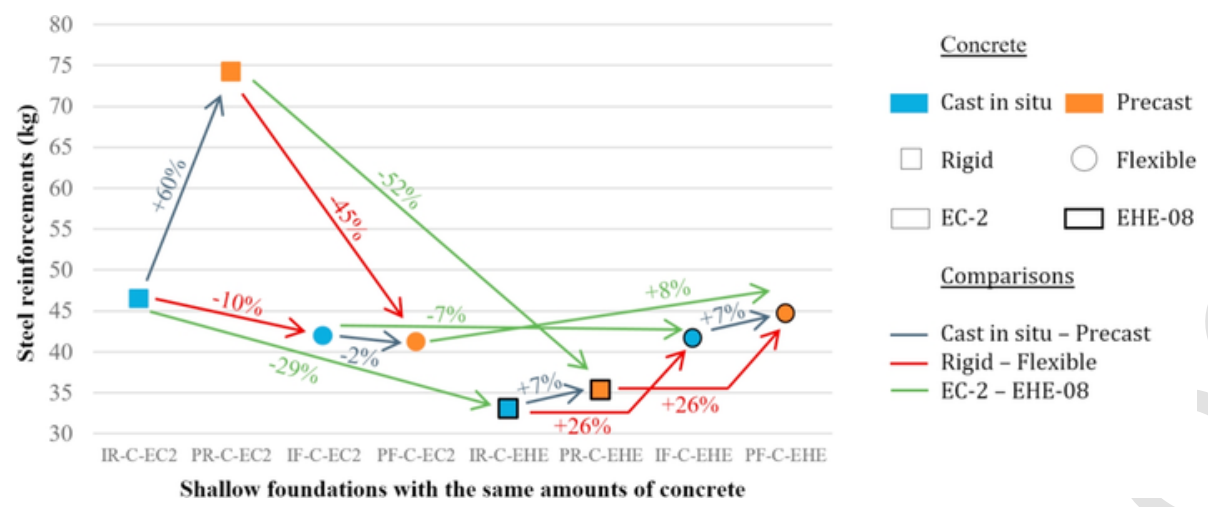

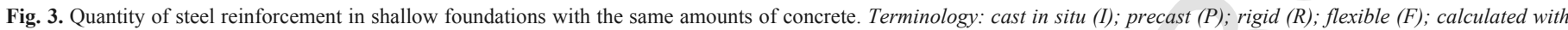
EC-2 (EC2); calculated with EHE-08 (EHE).

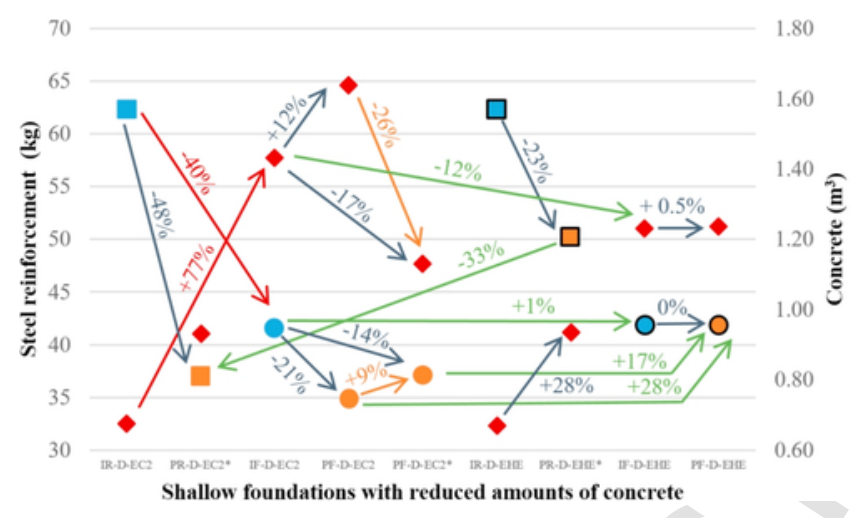
Concrete

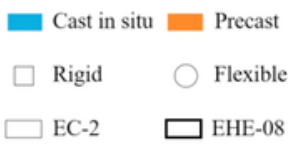

Comparisons

- Cast in situ - Precast

- Rigid - Flexible

- Single - Sloped (precast)

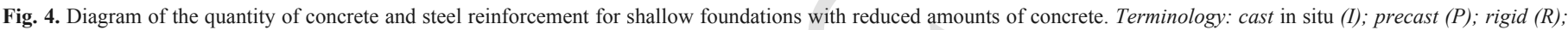
flexible (F); calculated with EC-2 (EC2); calculated with EHE-08 (EHE).

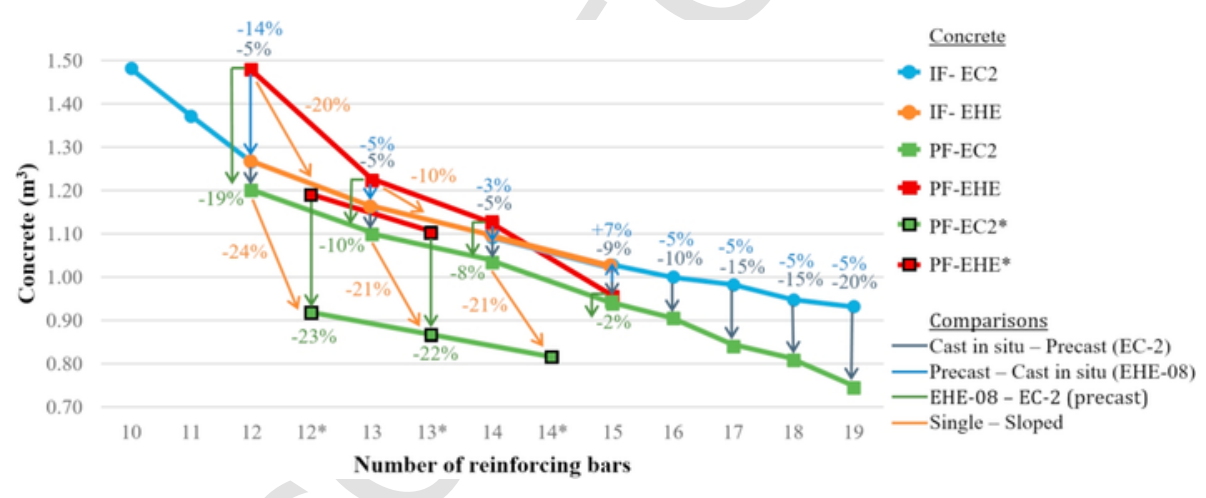

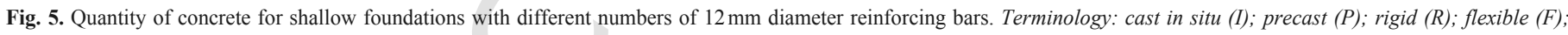
calculated with EC-2 (EC2); calculated with EHE-08 (EHE).

EHE-08 had to comply with the minimum mechanical amount and the restriction on CSF depths of no less than $25 \mathrm{~cm}$. Moreover, the precast sloped CSFs calculated with EC-2 (PF-EC2*) required up to $23 \%$ less concrete (PF-EHE*) for the same reasons. Besides, the precast CSFs presented around 5\% more reinforcement with the same number of reinforcing bars compared to the cast-in-situ CSFs, because of their thinner concrete covers.

\subsection{Environmental assessment of CSFS}

The results of the structural analysis showed the influence of the selected variables of the study on the structural design. The aim in this section is to show the influence of the selected variables on the environmental burdens, considering the LCA stages from cradle to gate.

In the first scenario, where all the CSFs have the same amount of concrete, the best solutions were the cast-in-situ flexible CSFs (IF-C-EC2 and IF-C-EHE), as shown in Table 4. If implemented, these solutions could reduce impacts by a minimum of $45 \%$ in all impact categories with respect to PR-C-EC2, which is the worst option, due to the extensive use of concrete and steel. In the cast-in-situ flexible CSFs, concrete and steel reinforcement account for around $95 \%$ of impacts in all categories. In addition, concrete accounts for $65 \%$ of 
Table 4

Comparison of environmental impacts of shallow foundations with the same amounts of concrete. (Percentage relative to the worst option for each environmental category).

\begin{tabular}{|l|l|l|l|l|l|l|l|l|}
\hline Foundations & GWV & ODP & TAP & FEP & POFP & MDP & FDP & CED \\
\hline IR-C-EC2 & $69 \%$ & $62 \%$ & $68 \%$ & $66 \%$ & $67 \%$ & $63 \%$ & $64 \%$ & $64 \%$ \\
\hline PR-C-EC2 & $100 \%$ & $100 \%$ & $100 \%$ & $100 \%$ & $100 \%$ & $100 \%$ & $100 \%$ & $100 \%$ \\
\hline IF-C-EC2 & $41 \%$ & $38 \%$ & $45 \%$ & $51 \%$ & $42 \%$ & $55 \%$ & $41 \%$ & $41 \%$ \\
\hline PF-C-EC2 & $50 \%$ & $50 \%$ & $53 \%$ & $53 \%$ & $53 \%$ & $55 \%$ & $51 \%$ & $51 \%$ \\
\hline IR-C-EHE & $65 \%$ & $59 \%$ & $60 \%$ & $53 \%$ & $61 \%$ & $47 \%$ & $59 \%$ & $59 \%$ \\
\hline PR-C-EHE & $88 \%$ & $89 \%$ & $79 \%$ & $63 \%$ & $83 \%$ & $52 \%$ & $84 \%$ & $84 \%$ \\
\hline IF-C-EHE & $41 \%$ & $38 \%$ & $45 \%$ & $51 \%$ & $42 \%$ & $55 \%$ & $41 \%$ & $41 \%$ \\
\hline PF-C-EHE & $51 \%$ & $51 \%$ & $55 \%$ & $57 \%$ & $55 \%$ & $59 \%$ & $53 \%$ & $52 \%$ \\
\hline
\end{tabular}

Terminology: cast in situ $(I)$; precast $(P)$; rigid $(R)$; flexible $(F)$; calculated with EC-2 (EC2); calculated with EHE-08 (EHE); GWP=Global Warming Potential; ODP $=$ Ozone Depletion Potential; TAP $=$ Terrestrial Acidification Potential; $F E P=$ Freshwater Eutrophication Potential; $P O F P=$ Photochemical Oxidant Formation Potential; $M D P=$ Mineral Depletion Potential; FDP =Fossil Depletion Potential; and, $C E D=$ Cumulative Energy Demand.

GWP emissions, while steel reinforcement accounts for 30\% of GWP emissions.

There again, all precast foundations have higher impacts compared to the versions that are cast in situ, because precast concrete has more impact per cubic meter. Accordingly, each cubic meter of precast concrete results in $20-60 \%$ more impacts in all categories (considering all construction items except steel reinforcement). The higher volumes of cement in the precast concrete, the lengthier transportation distance (considered $150 \mathrm{~km}$ ), and the need for mechanized on-site installation mean that the precast products have the highest environmental impacts. In addition, precast products often require more steel reinforcement, because of higher concrete strengths and thinner concrete covers. Consequently, the precast CSFs might account for around 35\% more impacts in all indicators compared to the cast-in-situ versions, where both have the same concrete volumes.

Moreover, the rigid CSFs recorded higher impacts in almost all categories compared to the flexible CSFs, as their concrete volumes were over twice as high. As regards the codes, the rigid CSFs calculated with EC-2 had higher environmental burdens (in particular the PR-C-EC2, as explained above); while the cast-in-situ flexible CSFs yielded similar environmental impacts for both codes, because of the similar amounts of steel reinforcement. Nevertheless, the precast flex- ible CSF calculated with EC-2 gave better results, because less steel reinforcement is required.

When assessing CSFs with reduced concrete geometries, smaller differences between the alternatives under assessment are observed, as concrete is one of the biggest contributors to the construction of a CSF. Although steel has higher environmental burdens for the same volume, CSFs are principally made of concrete. For the sake of simplification, the results obtained for FDP and TAP are not shown in Fig. 6 , because they show a similar trend to CED.

The single cast-in-situ CSFs were environmentally more promising (IF-D-EC2; IR-D-EHE; IF-D-EHE) compared to the precast versions (PF-D-EC2; PR-D-EHE*; PF-D-EHE), because the amounts of concrete (PF-D-EHE), or concrete and steel reinforcement (PF-D-EC2; PR-D-EHE*) were not sufficiently reduced to compensate the higher impacts of precast concrete. Nevertheless, when concrete was considerably reduced and steel reinforcement was not significantly increased, the environmental performance of the precast foundations was similar or better than the performance of the cast-in-situ versions. This improvement is mainly explained by the use of sloped shapes. Hence, the precast flexible CSFs calculated with EC-2 (PF-D-EC2*) resulted in lower impacts in four out of eight categories (IF-D-EC2); and the precast rigid CSFs calculated with EC-2 (PR-D-EC2*) resulted in lower impacts in five out of eight categories (IR-D-EC2).

In general, rigid CSFs had higher impacts in most categories compared to flexible CSFs, because of their larger volumes of concrete. The exception was the precast rigid CSF calculated with EC2 (PR-D-EC2* compared to PF-D-EC2), which had up to $35 \%$ fewer impacts, because of the lower quantity of steel reinforcement (due to the use of sloped shapes, as explained above). However, a higher steel reinforcement was required when the reduction in concrete was obtained decreasing the depth of the CSF. Nevertheless, the depth restriction in the specifications of EHE-08 limits the environmental burdens derived from steel reinforcement. Moreover, flexible CSFs had the most highly rated impacts in the categories of FEP and MDP, because of the amounts of reinforcement.

Additionally, the foundations built in accordance with EHE-08 were environmentally preferable, showing impacts up to $10 \%$ lower than foundations calculated with EC-2. Nevertheless, when the precast foundations were compared, the sloped CSFs calculated with

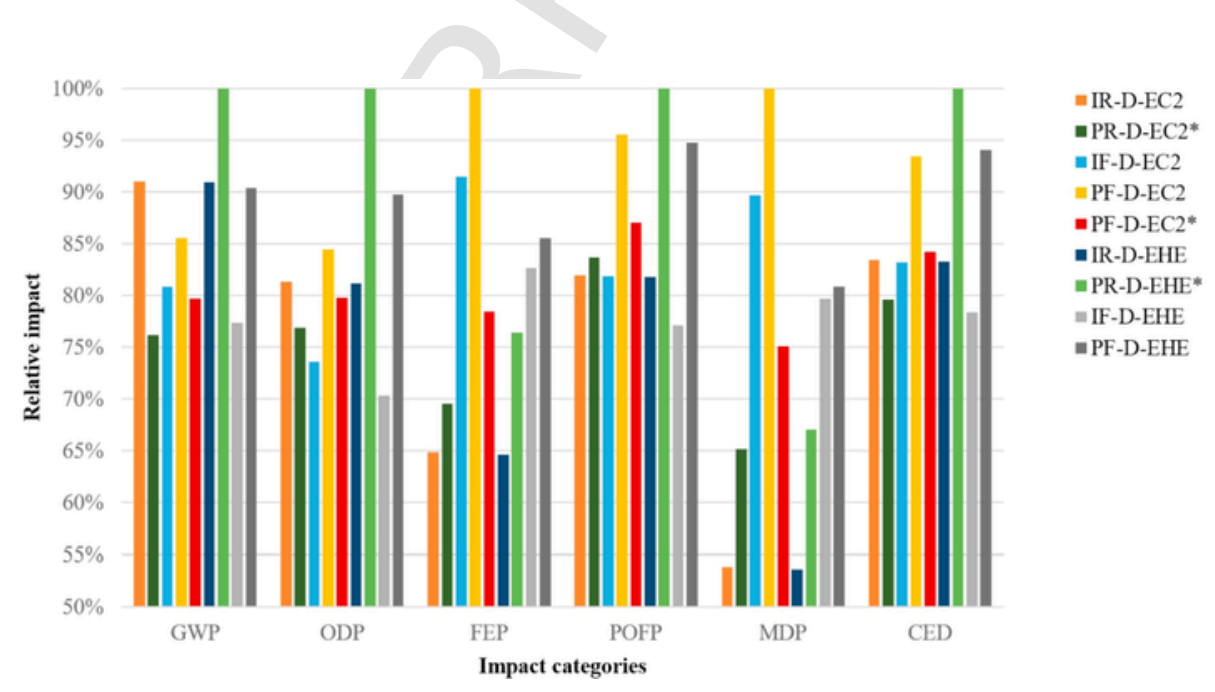

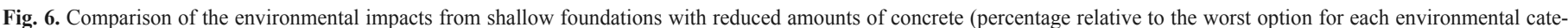

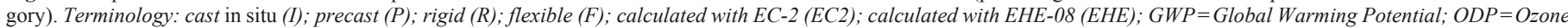

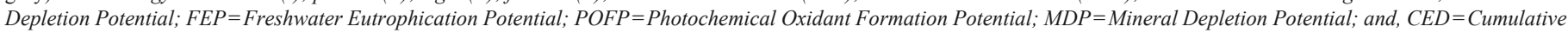
Energy Demand. 
EC-2 were the best option, due to the great reduction in the use of concrete and steel reinforcement. This result is not only explained by the use of sloped shapes, but also because EC-2 permits lower depths than EHE-08. Thus, these foundations had lower impacts in all categories: up to $10 \%$ for the flexible CSF (PF-D-EC2* compared to PF-D-EHE) and more than $20 \%$ in four out of eight categories for the rigid CSF (PR-D-EC2* compared to PR-D-EHE*).

In Fig. 7, the environmental impacts of five representative CSFs in the study that exemplify the overall results are depicted. Again, for the sake of simplicity, the results obtained for TAP and FDP with similar trends to CED are not shown.

The best alternative was the cast-in-situ flexible CSF calculated with EHE-08 (IF-S13-EHE). Nevertheless, the cast-in-situ flexible CSF calculated with EC-2 (IF-S13-EC2) differed by only $1 \%$ in terms of its impacts; and the precast rigid sloped CSF calculated with EC-2 differed by $1-4 \%$ (PR-D-EC2*). Therefore, while there is a logical correspondence between variables and environmental impacts, the most important factor is the optimization of materials. For in- stance, an optimized-materials foundation (IF-S13-EHE) gave better results in all impact categories compared to a regular foundation (IR-C-EHE) in Spain: around 25\% more impacts in six out of eight categories. Moreover, the combination of study variables can represent a variation in impacts of between 45 and $60 \%$ in all indicators. Additionally, foundations are sometimes oversized, because it is cheaper to use a non-optimized standardized solution than to design a specific one. This surplus of materials is frequently used for safety construction purposes, as foundations are buried in the ground that makes them difficult to monitor.

Fig. 8 shows the environmental burdens in relation to the construction items of three representative optimal solutions (IF-S13-EHE, PF-S13-EC2*, PR-D-EC2*, with reduced concrete volumes) and a regular solution in Spain (IR-C-EHE). Again, for the sake of simplicity, the results obtained for ODP and FDP with similar trends to CED are not shown.

Concrete and steel reinforcement had the highest impacts in all categories. They accounted for up to $95 \%$ of GWP emissions in cast-

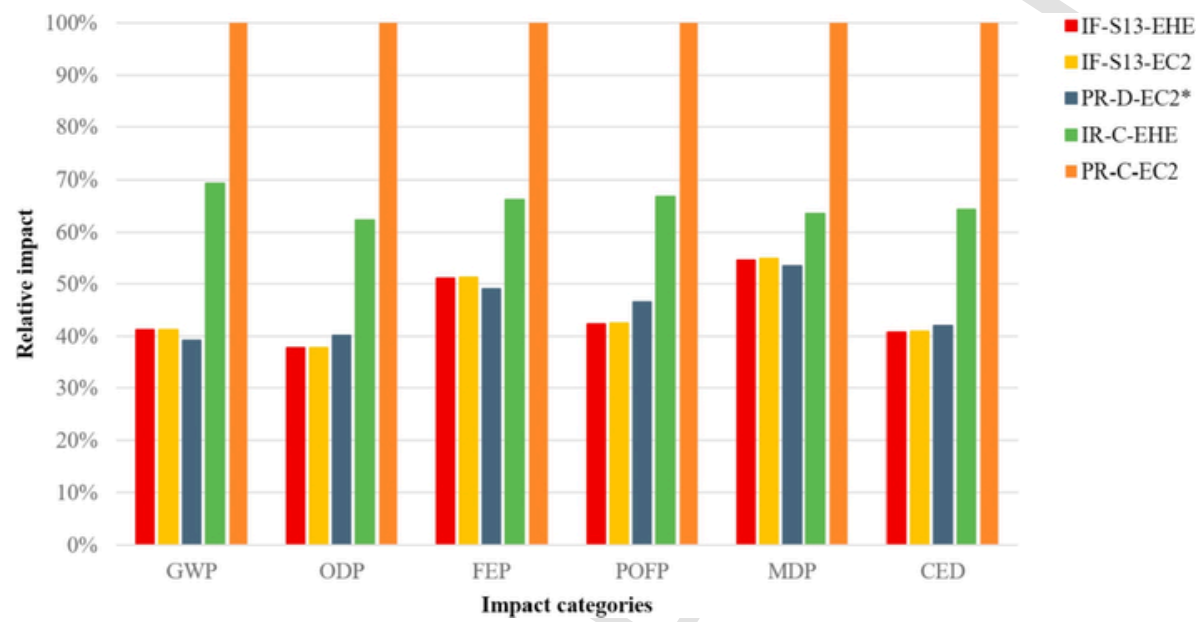

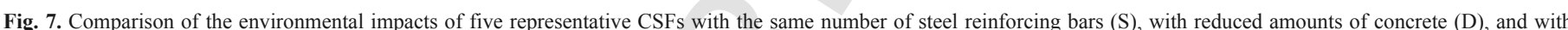

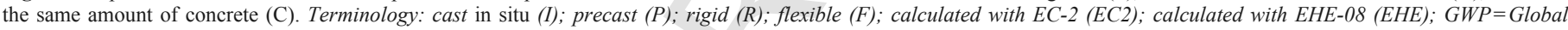

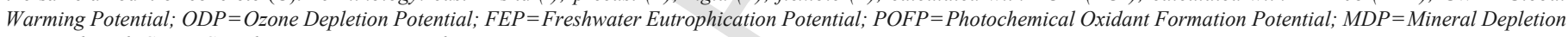
Potential; and, CED =Cumulative Energy Demand.

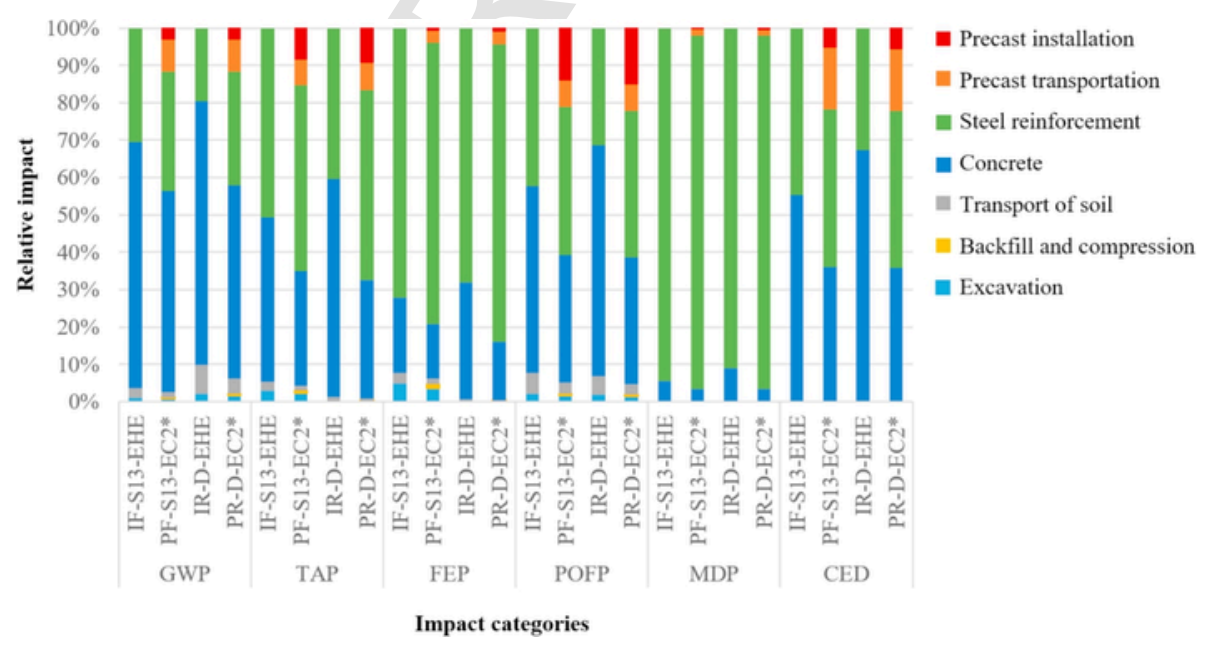

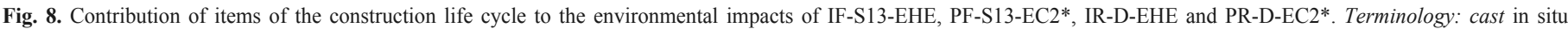

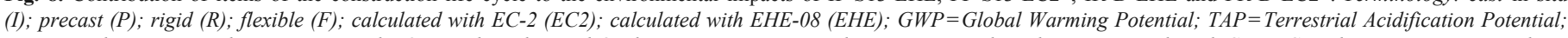
FEP $=$ Freshwater Eutrophication Potential;POFP = Photochemical Oxidant Formation Potential; MDP=Mineral Depletion Potential; and, CED=Cumulative Energy Demand. 
in-situ foundations; and around $85 \%$ of GWP emissions in precast foundations. This difference is due to the larger concrete volumes used in cast-in-situ CSFs. In addition, transport and installation of precast units accounted for more than $20 \%$ of impacts in four out of the eight indicators.

Although the prefabrication of foundations helps to control the amount of material and waste and reduce unforeseen events, it usually implies oversizing the construction, because not all sizes are produced and available in the factory. Construction design that takes into account the available sizes and the characteristics of the construction system is therefore important, so that the amount of materials and the corresponding impacts are reduced.

\section{Conclusions}

A structural analysis embedded within a Life Cycle Analysis (LCA) methodology has been used to assess the influence of certain key variables on the environmental impacts of the construction of concrete shallow foundations (CSFs). These variables were: built cast in situ or precast; rigid or flexible; and calculated with structural design code EC-2 or EHE-08.

One main conclusion drawn from the results is that decision-makers should consider some key aspects of the traditional design and construction of CSFs, because they can significantly affect environmental performance. For instance, steel and concrete had the highest impacts in all impact categories, accounting for around 95\% of GWP emissions for cast-in-situ CSFs and $85 \%$ for precast CSFs. In addition, careful selection of the variables in the study might vary all indicators of the environmental impacts of CSFs by $45-60 \%$. The optimization of concrete and steel amounts, when considering the variables selected for this study, is therefore a crucial element to minimize the impacts.

Compared with the cast-in-situ CSFs, the precast CSFs resulted in increases of up to around $35 \%$ in all impact categories, when both types had the same volume of concrete but different amounts of steel. These higher impacts are partly due to the higher cement content of precast concrete. In addition, precast products require lengthier transport distances and the use of on-site mechanized installation, as well as tending to require more reinforcing steel for higher concrete strengths. In this regard, the different minimum quantities of steel established by each structural code (EC-2 and EHE-08) for precast CSFs might affect the environmental impacts with variations of up to $48 \%$. Nevertheless, when precast concrete volumes are greatly reduced and steel reinforcement is not significantly increased, the findings make it clear that precast CSFs can achieve similar environmental impacts to cast-in-situ CSFs. For instance, the precast rigid sloped CSF calculated with EC-2 (PR-D-EC2*) had impacts that were around 2\% higher than the best option in the study (IF-S13-EHE). This observation is principally explained by the use of sloped shapes and because it was calculated with EC-2 that permits greater reductions of concrete than EHE-08, as the minimum depth of the CSF is not limited. This code-dependent variability comes from the different assumptions adopted in each one. These assumptions, deduced from specific behavioural models, are basically structural or related to durability.

This study has shown that the best solutions from an environmental perspective are cast-in-situ and flexible CFS with moderate depths (less steel), or precast with considerable reductions in concrete volumes (sloped shapes); and calculated with the EHE-08 code, if they are cast in situ, or with the EC-2 structural code, if they are precast. However, each case (loads, soil type, structural settlement, and others) and its related variables should be specifically studied, taking into account that a shallow foundation may be unfeasible and that other types of foundations (for instance deep ones) may be preferable or necessary. The consideration of the environmental criteria that have been defined in this study can significantly help to reduce the impacts of CSFs with relatively little effort.

\section{Acknowledgements}

The authors are grateful for the help and support of Prof. Josep Ignasi de Llorens, Prof. Albert de la Fuente, Jaume Vallès (Arch.), Antony Ross Price, SosteniPra, GAT-UPC (Grup d'Arquitectura i Tecnologia), and ANEFHOP (Asociación Nacional Española Fabricantes de Hormigón Preparado).

This research did not receive any specific grant from funding agencies in the public, commercial, or not-for-profit sectors.

\section{References}

Abd Rashid, A.F., Yusoff, S., 2015. A review of life cycle assessment method for building industry. Renew. Sustain. Energy Rev. 45, 244-248 https://doi.org/10. 1016/j.rser.2015.01.043.

Calavera Ruiz, J., 2008. Proyecto y cálculo de estructuras de hormigón, second ed. Instituto Técnico de Materiales y Construcciones, Madrid.

Chiang, Y.-H., Hon-Wan Chan, E., Ka-Leung Lok, L., 2006. Prefabrication and barriers to entry - a case study of public housing and institutional buildings in Hong Kong. Habitat Int. 30, 482-499 https://doi.org/10.1016/j.habitatint.2004.12.004.

CTE-SE-C, 2008. Structural Safety. Foundations. Spanish Technical Building Code.

CYPE Ingenieros, 2017. CYPECAD V2018. http://www.cype.es/, (accessed 17.01.18).

EHE-08, 2008. Spanish Structural Concrete Code.

EN 15804:2012+A1:2014, 2014. Sustainability of construction works. Environmental Product Declarations. Core Rules for the Product Category of Construction Products.

EN 1991-1-1, 2002. Eurocode 1: Actions on Structures - Part 1-1: General Actions Densities, Self-weight, Imposed Loads for Buildings.

EN 1992-1-1, 2004. Eurocode 2: Design of Concrete Structures.

EN 1997-1, 2004. Eurocode 7: Geotechnical Design.

Ghattas, R., Gregory, J., Olivetti, E., Greene, S., 2013. Life Cycle Assessment for Residential Buildings: a Literature Review and Gap Analysis. Massachusetts Institute of Technology https://cshub.mit.edu/sites/default/files/documents/ LCAforResidentialBuildings.pdf, (accessed 17.01.18).

Goedkoop, M., Heijungs, R., Huijbregts, M., De Schryver, A., Struijs, J., van Zelm, Rosalie, 2013. ReCiPe 2008. http://www.rivm.nl/en/Topics/L/Life_Cycle Assessment LCA/Downloads/, (accessed 17.01.18).

González, M.J., García Navarro, J., 2006. Assessment of the decrease of $\mathrm{CO}_{2}$ emissions in the construction field through the selection of materials: practical case study of three houses of low environmental impact. Build. Environ. 41, 902-909 https://doi.org/10.1016/j.buildenv.2005.04.006.

Hormiconsa, 2011. Determination of the Volumetric Variation of a Soft Concrete by the Effect of Vibration-compaction and Settlement.

ISO 14040:2006, 2006. Environmental Management - Life Cycle Assessment - Principles and Framework.

ISO 14044:2006, 2006. Environmental Management - Life Cycle Assessment - Requirements and Guidelines.

ITeC, 2017. Online ITeC Database: Prices, Technical Details, Companies, Certificates, Product Pictures and Environmental Data. https://itec.cat/, (accessed 17.01.18).

Kamali, M., Hewage, K., 2017. Development of performance criteria for sustainability evaluation of modular versus conventional construction methods. J. Clean. Prod. 142, 3592-3606 https://doi.org/10.1016/j.jclepro.2016.10.108.

Li, Z., Shen, G.Q., Alshawi, M., 2014. Measuring the impact of prefabrication on construction waste reduction: an empirical study in China. Resour. Conserv. Recycl 91, 27-39 https://doi.org/10.1016/j.resconrec.2014.07.013.

Mao, C., Shen, Q., Shen, L., Tang, L., 2013. Comparative study of greenhouse gas emissions between off-site prefabrication and conventional construction methods: two case studies of residential projects. Energy Build. 66, 165-176 https://doi.org/ 10.1016/j.enbuild.2013.07.033.

Monahan, J., Powell, J.C., 2011. An embodied carbon and energy analysis of modern methods of construction in housing: a case study using a lifecycle assessment framework. Energy Build. 43, 179-188 https://doi.org/10.1016/j.enbuild.2010.09. 005 .

Ondova, M., Estokova, A., 2016. Environmental impact assessment of building foundation in masonry family houses related to the total used building materials. Environ. Prog. Sustain. Energy 35, 1113-1120 http://doi.org/10.1002/ep.12307. 
PRé Consultants, 2016. SimaPro 8.2.3.0. https://www.pre-sustainability.com/, (accessed 17.01.18)

Pujadas, E., de Llorens, J.I., Moonen, S.P.G., 2013. Prefabricated foundations for 3D modular housing. In: 39th World Congress on Housing Science: Changing Needs, Adaptive Buildings, Smart Cities. IAHS, Milan.

Ritter, W., 1899. Die bauweise hennebique (Hennebiques construction method). Schweiz. Bauztg. 33, 59-61 https://www.e-periodica.ch/cntmng?pid=sbz-002: 1899:33:34::57, (accessed 17.01.18).

Rose Inman, M., Houlihan Wiberg, A., 2015. Life Cycle GHG Emissions of Material Use in the Living Laboratory. SINTEF Academic Press, Trondheim https://www. sintefbok.no/book/index/1056, (accessed 17.01.18).

Sandanayake, M., Zhang, G., Setunge, S., 2016. Environmental emissions at foundation construction stage of buildings - two case studies. Build. Environ. 95, 189-198 https://doi.org/10.1016/j.buildenv.2015.09.002.

Sanjuan-Delmás, D., Hernando-Canovas, E., Pujadas, P., de la Fuente, A., Gabarrell, X., Rieradevall, J., Josa, A., 2015. Environmental and geometric optimisation of cylindrical drinking water storage tanks. Int. J. Life Cycle Assess. 20, 1612-1624 https://doi.org/10.1007/s11367-015-0963-y.

Sartori, I., Hestnes, A.G., 2007. Energy use in the life cycle of conventional and low-energy buildings: a review article. EnergyBuild 39, 249-257 https://doi.org/ 10.1016/j.enbuild.2006.07.001.

Swiss Centre for Life Cycle Inventories, 2016. Ecoinvent v3.3. http://www.ecoinvent. org/, (accessed 17.01.18).

Tam, V.W.Y., Tam, C.M., Zeng, S.X., Ng, W.C.Y., 2007a. Towards adoption of prefabrication in construction. Build. Environ. 42, 3642-3654 https://doi.org/10.1016/ j.buildenv.2006.10.003
Tam, V.W.Y., Tam, C.M., Ng, W.C.Y., 2007b. On prefabrication implementation for different project types and procurement methods in Hong Kong. J. Eng. Des. Technol. 5, 68-80 http://www.emeraldinsight.com/doi/abs/10.1108/ 17260530710746614, (accessed 17.01.18).

The Concrete Centre, 2009. Sustainability Performance Report. 1st Report http://www. sustainableconcrete.org.uk/PDF/SCS\%20Performance\%20Report\%20FINAL.pdf, (accessed 17.01.18).

UNEP, 2009a. Buildings and Climate Change. Summary for Decision Makers. https:// europa.eu/capacity4dev/unep/document/ buildings-and-climate-change-summary-decision-makers/, (accessed 17.01.18)

UNEP, 2009b. Common Carbon Metric for Measuring Energy Use \& Reporting Greenhouse Gas Emissions from Building Operations. http://www.sballiance.org/ wp-content/uploads/2014/04/Common-Carbon-Metric-2009.pdf, (accessed 17.01.18).

United Nations, 2017. World Population Prospects. The 2017 Revision. https:/esa.un. org/unpd/wpp/Publications/Files/WPP2017_KeyFindings.pdf, (accessed 17.01.18)

Wong, R., Hao, J., Ho, C., 2003. Prefabricated Building Construction Systems Adopted in Hong Kong. https://www.researchgate.net/publication/265071247 Prefabricated_Building_Construction_Systems_Adopted_in_Hong_Kong/, (accessed 17.01.18).

Wren, C., 2012. Modular foundations and retaining walls. ICE Man. Geotech. Eng. 2 , $1343-1350$.

Yasantha Abeysundara, U.G., Babel, S., 2010. A quest for sustainable materials for building elements in Sri Lanka: Foundations. Environ. Prog. Sustain. Energy 29, 370-381 http://doi.org/10.1002/ep.10420. 